\title{
Pencegahan Penyalahgunaan Gadget dan Perlindungan Anak pada Siswa SMAIT Daarul' IImi Bandar Lampung
}

\author{
Maroni, Erna Dewi, Rini Fathonah, Damanhuri Warganegara, Nenny Dwi Ariani, Mashuril Anwar \\ Fakultas Hukum Universitas Lampung, Bandar Lampung \\ Jl. Prof. Dr. Soematri Brojonegoro No.1, Bandar Lampung, 35141, Indonesia
}

\begin{abstract}
ARTICLE INFO:
Received: 2020-04-17 Revised: $2020-06-26$

Accepted: 2020-08-06
\end{abstract}

\section{Keywords:}

Child protection;

Focus group

discussion; Gadget

abuse; Prevention;

Socialization

\section{ABSTRACT}

In general, the students at SMAIT Daarul IImi do not understand about the prevention of gadget abuse and child protection properly. They also have never received legal counseling regarding gadget abuse and child protection. Thus, it is necessary to provide good knowledge and understanding through socialization and focus group discussions (FGD) to overcome partner problems related to the prevention of gadget abuse and child protection among students of SMAIT Daarul IImi, Bukit Kemiling Permai, Bandar Lampung City. This program includes providing knowledge and understanding, prevention of gadget abuse, and child protection. Then proceed with discussion and question and answer, and test the participants' understanding by giving a pre-test and post-test. The results of the program show that this socialization and focus group discussion (FGD) activity is important to increase public knowledge, understanding and legal awareness regarding the prevention of gadget abuse and child protection. This program contributes to preventing the adverse effects of technological change.

(c) 2020 Published by University of Merdeka Malang. This is an open access article distributed under the CC BY-SA 4.0 license (https://creativecommons.org/licenses/by-sa/4.0/

How to cite: Maroni, Dewi, E., Fathonah, R., Warganegara, D., Ariani, N. D., \& Anwar, M. (2020). Pencegahan Penyalahgunaan Gadget dan Perlindungan Anak pada Siswa SMAIT Daarul' IImi Bandar Lampung. Abdimas: Jurnal Pengabdian Masyarakat Universitas Merdeka Malang, 5(3), 257-265. https://doi.org/10.26905/abdimas.v5i3.3405

\section{PENDAHULUAN}

Kemajuan teknologi sekarang ini sangat pesat dan semakin canggih. Banyak teknologi canggih yang telah diciptakan membuat perubahan yang begitu besar dalam kehidupan manusia di berbagai bidang. Sepertinya gadget dapat memberikan dampak yang begitu besar pada nilai-nilai kebudayaan. Setiap orang di seluruh dunia hampir dapat dipastikan sudah memiliki gadget semua, bahkan tak jarang banyak orang yang memiliki lebih dari satu gadget. Ini mungkin disebabkan oleh beberapa faktor. Pengguna gadget saat ini tidak hanya berasal dari kalangan pekerja. Tetapi hampir semua kalangan termasuk anak 
ABDIMAS: Jurnal Pengabdian Masyarakat Universitas Merdeka Malang

Volume 5, No 3, November 2020: 257-265

(Chusna, 2017). Gadget para era digital seperti ini merupakan benda yang sudah tidak bisa dipisahkan dari aktifitas sehari-hari. Di era globalisasi ini, pengguna gadget di Indonesia mengalami peningkatan pesat. Bahkan diperkirakan pengguna gadget di Indonesia akan melampaui jumlah penduduk Indonesia. Data menunjukkan bahwa pada tahun 2020 pengguna gadget di Indonesia mencapai 338,2 juta jiwa (Haryanto, 2020), dimana 79,5\% diantaranya berasal dari kategori anak-anak (Zaini \& Soenarto). Penggunaan gadget di Indonesia digunakan untuk berbagai macam keperluan, dari mencari informasi, bermain game hingga mencari hiburan. Kenyataannya 160 juta jiwa atau 59\% masyarakat Indonesia menggunakan gadget untuk mengakses media sosial seperti WhatsApp, Instagram, TikTok, Facebook, dan sebagainya (Haryanto, 2020). Dampak yang ditimbulkan pun berbagai macam, dari positif hingga dampak negatif yang dapat merugikan diri sendiri serta orang lain. Pengawasan penggunaan gadget sangat penting, apalagi kini penggunaan gadget sudah tak dibatasi umur dan waktu.

Kemudahan mengakses dunia maya melalui gadget memang mempunyai dampak positif, diantaranya dalam pola pikir anak yaitu mampu membantu anak dalam mengatur kecepatan bermainnya, mengolah strategi dalam permainan, dan membantu meningkatkan kemampuan otak kanan anak selama dalam pengawasan yang baik. Akan tetapi dibalik kelebihan tersebut lebih dominan pada dampak negatif yang berpengaruh terhadap perkembangan anak, diantaranya anak mengalami gangguan kesehatan, kecanduan akut maupun terpapar paparan negatif seperti pornografi dan kekerasan. Salah satu kasus penyalahgunaan gadget di Indonesia yakni kasus dua remaja asal bekasi yang mengalami gangguan jiwa. Remaja berinisial NV (17) dan TY (17) dalam kesehariannya hanya termenung namun bereaksi ketika melihat telepon genggam (Makki, 2019). Oleh karena itu, penggunaan gadget oleh anak perlu diawasi agar tidak disalahgunakan fungsinya. Namun nyatanya orangtua belakangan ini beranggapan bahwa gadget mampu menjadi teman bagi anak sehingga peran orangtua sudah tergantikan oleh gadget. Padahal informasi yang diakses melalui gadget dapat pula memuat konten-konten negatif. Oleh karenanya, untuk melindungi masa depan anak diperlukan peran orangtua dalam mengawasi penggunaan gadget oleh anak. Sesuai dengan UU No. 23 Tahun 2002 sebagaimana yang telah diubah dengan UU No. 35 Tahun 2014 tentang Perlindungan Anak, bentuk perlindungan terhadap anak salah satunya yaitu hak untuk memperoleh pengetahuan positif dalam kondisi pesatnya perkembangan bidang teknologi informasi (Rudiantara, 2018). Mengingat kesejahteraan anak tidak hanya meliputi aspek sosial dan ekonomi saja, maka implementasi perlindungan anak sebagaimana yang diamanatkan oleh Undang-Undang Perlindungan Anak memiliki lingkup yang luas. Bentuk implementasi Undang-Undang Perlindungan Anak antara lain perlindungan anak di bidang peradilan, perlindungan anak dari kekerasan, perlindungan anak dari eksploitasi fisik, mental, dan sosial, serta perlindungan dari perlakuan diskriminasi agar anak dapat tumbuh dan berkembang secara wajar (Roria, 2019). Implementasi Undang-Undang Perlindungan Anak mutlak harus dilakukan, karena perlindungan anak merupakan manifestasi keadilan dalam masyarakat (Anwar \& Wijaya, 2019).

Program ini bertujuan untuk memberikan pemahaman pada anak tentang pengaruh gadget agar daya kembang anak dapat berkembang dengan baik dan menjadi anak yang aktif, cerdas, dan interaktif terhadap orang lain. Penyalahgunaan gadget akan berdampak buruk bagi pola pikir (Nurhaeda, 2018), tumbuh kembang anak maupun lingkungan sosial dan pola tingkah lakunya (Rahman, 2016). Oleh karenanya dilakukan kegiatan Sosialisasi dan Focus Group Discussion (FGD) tentang pencegahan penyalahgunaan gadget dan perlindungan anak pada siswa SMAIT Daarul' Ilmi, Bukit Kemiling Permai Kota Bandar Lampung. 


\section{METODE}

Kegiatan ini dilakukan dengan menggunakan metode ceramah, diskusi dan tanya jawab. Penggunaan metode ceramah sabanyak 50\%, diskusi $25 \%$ dan tanya jawab 25\%. Metode ini digunakan agar materi yang disampaikan mudah dipahami oleh peserta. Selain itu, untuk menguji pemahaman peserta juga diberikan soal pre test dan post test. Tim menyampaikan materi dengan cara ceramah dengan menggunakan LCD yang sudah disiapkan sebelumnya, peserta sangat antusias dan serius menyimak serta memperhatikan dan mendengarkan dengan seksama di dalam kegiatan penyuluhan hukum ini. Kemudian dilanjutkan dengan diskusi dan tanya jawab antara peserta dengan pemateri mengenai pencegahan penyalahgunaan gadget dan perlindungan anak.

Metode yang diterapakan dalam pelaksanaan kegiatan Sosialisasi dan Focus Group Discussion (FGD) tentang pencegahan penyalahgunaan gadget dan perlindungan anak pada siswa SMAIT Daarul' Ilmi, Bukit Kemiling Permai Kota Bandar Lampung sebagai berikut: (1) Tim menyampaikan materi dengan cara menggunakan LCD yang sudah disiapkan sebelumnya, peserta sangat antusias dan serius menyimak serta memperhatikan dan mendengarkan dengan seksama di dalam kegiatan Sosialisasi dan Focus Group Discussion (FGD) ini. (2) Diskusi dan tanya jawab mengenai hak-hak mereka untuk memperoleh pengetahuan positif sesuai UU No. 23 Tahun 2002 sebagaimana yang telah diubah dengan UU No. 35 Tahun 2014 tentang Perlindungan Anak.

Secara keseluruhan kegiatan Sosialisasi dan Focus Group Discussion (FGD) Pencegahan Penyalahgunaan Gadget dan Perlindungan Anak pada Siswa SMAIT Daarul Ilmu Bukit Kemiling Permai, Kota Bandar Lampung dilaksanakan melalui tahapan-tahapan sebagai berikut ini: (1) Tahap Persiapan, persiapan dilakukan selama 10 hari dengan kegiatan mempersiapkan administrasi kegiatan seperti surat perizinan dan perlengkapan lainnya, menggandakan materi kegiatan, daftar pertanyaan, peninjauan ke lokasi kegiatan termasuk pula pendekatan sosial kepada SMAIT Daarul Ilmi. (2) Tahap Pelaksanaan, kegiatan penyuluhan ini dilakukan selama 1 hari dengan ketentuan awal kegiatan yaitu: (a) melaksanakan evaluasi awal (pretest); (b) penyampaian materi kegiatan; (c) diskusi dan tanya jawab; (d) melaksanakan evaluasi akhir (posttest). (3) Tahap Akhir, selama 19 hari dengan kegiatan evaluasi akhir, penyusunan dan penggandaan laporan kegiatan, penyerahan laporan hasil kegiatan, perbaikan-perbaikan ke Lembaga Pengabdian kepada masyarakat Universitas Lampung.

\section{HASIL DAN PEMBAHASAN}

Gadget atau gawai merupakan peranti yang memiliki fungsi praktis dan spesifik yang dirancang lebih canggih dari teknologi sebelumnya (Pertiwi, 2020). Kegiatan pengabdian kepada masyarakat ini difokuskan pada pencegahan penyalahgunaan gadget dalam rangka melindungi anak, hal ini dilakukan mengingat gadget tidak hanya mempunyai fungsi positif namun dapat berdampak negatif terutama bagi anak-anak. Bagi anak gadget bagaikan pisau bermata dua, satu sisi memberikan dampak positif namun di sisi lain dapat menimbulkan dampak negatif (Setianingsih, 2019). Penggunaan gadget dapat memudahkan komukasi, gadget memiliki berbagai fitur untuk berinteraksi sehingga memudahkan dalam menambah dan menjalin hubungan kekerabatan, dan gadget dapat membantu dalam mengkases berbagai ilmu pengetahuan (Chusna, 2017). Di sisi lain, penggunaan gadget menimbulkan dampak negatif bagi anak antara lain: (1) Penglihatan terganggu; (2) Sakit kepala; (3) Mengganggu pendengaran; (4) Kelainan postur 
ABDIMAS: Jurnal Pengabdian Masyarakat Universitas Merdeka Malang Volume 5, No 3, November 2020: 257-265

tubuh; (5) Mengurangi daya tangkap otak; (6) Penyakit jantung dan stroke dini; (7) Kecanduan pornografi; (8) Ketergantungan; (9) Memicu tindakan kekerasan; (10) Anti sosial; (11) Kehilangan kesadaran diri (deindividualisasi); (12) Menyita keuangan.

Selain itu, penggunaan gadget yang tidak bijak akan merangsang anak melakukan tindakan kriminal. Perkembangan fitur dan jaringan pada gadget dapat menjadi media bagi anak untuk melakukan kejahatan komputerisasi (cybercrime). Tindak pidana cybercrime yang umum dilakukan oleh anak antara lain kejahatan ponografi (cyber porn), kejahatan kesusilaan (Manurung et al., 2016), dan pencurian dengan kekerasan/ begal (Dirgantara, 2020), penghinaan, pencemaran nama baik, pengancaman, dan pemerasan. Disfungsi gadget yang menimbulkan tindakan criminal ini akan menghadapkan anak pada masalah hukum. Berdasarkan ketentuan Pasal 27 Undang-Undang Nomor 11 Tahun 2008 tentang Informasi dan Transaksi Elektronik (UU ITE), setiap orang yang dengan sengaja dan tanpa hak mendistribusikan informasi elektronik yang memiliki muatan melanggar kesusilaan, perjudian, penghinaan, pencemaran nama baik, dan pemerasan diancam dengan pidana penjara paling lama 6 tahun dan denda paling banyak Rp. 1.000.000.000 (satu milyar rupiah). Selanjutnya berdasarkan ketentuan Pasal 29 UU ITE, setiap orang dengan sengaja menimbulkan ancaman kekerasan melalui informasi elektronik, diancam pidana paling lama 12 Tahun dan denda paling banyak Rp. 2.000.000.000 (dua milyar rupiah).

Khalayak sasaran yang hadir dalam kegiatan ini berjumlah 50 orang yang terdiri dari siswa SMAIT Daarul Ilmi dan beberapa guru. Evaluasi awal terhadap khalayak sasaran menunjukan bahwa sebagian besar siswa SMAIT Daarul Ilmi mempunyai gadget namun belum mengetahui dan memahami fungsi, dampak negatif, dan cara bijak penggunaan gadget.
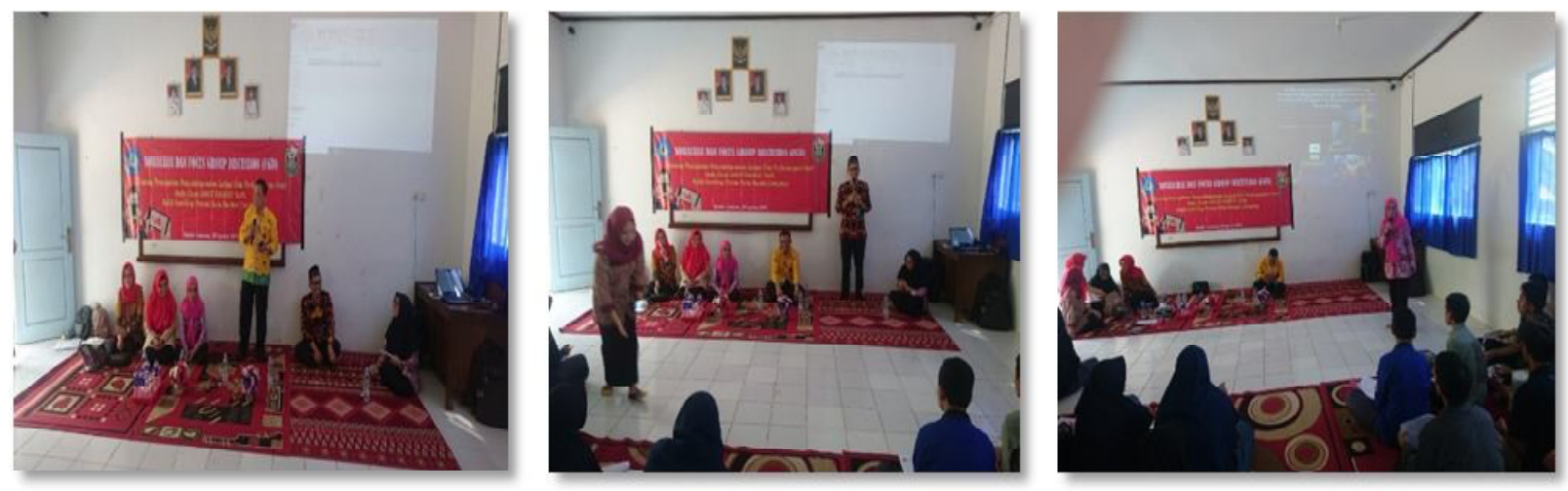

Gambar 1. Penyampaian materi kepada peserta pelatihan

Berdasarkan evaluasi awal, proses pelaksanaan dan akhir kegiatan terhadap khalayak sasaran kegiatan ini berhasil dengan baik. Keberhasilan ini dapat dilihat dari antusiasme siswa SMAIT Daarul Ilmi dalam mengikuti kegiatan ini dibuktikan dengan kehadiran 50 orang peserta. Selain itu, para peserta aktif baik dalam bertanya maupun dalam berdiskusi mengenai pencegahan penyalahgunaan gadget dan perlindungan anak. 
Tabel 1. Perbandingan pra penyampaian materi dan pasca penyampaian materi kegiatan

\begin{tabular}{lll}
\hline \multicolumn{1}{c}{ Unsur } & \multicolumn{1}{c}{ Pra Penyampaian Materi } & \multicolumn{1}{c}{ Pasca Penyampaian Materi } \\
\hline Dampak negatif gadget & Belum memahami dampak negatif & Sudah memahami dampak negatif \\
& gadget & gadget \\
Upaya pencegahan & Belum memahami upaya & Sudah memahami dan mengerti \\
penyalahgunaan gadget & pencegahan penyalahgunaan & mengenai upaya pencegahan \\
& gadget & penyalahgunaan gadget \\
UU No. 11 Tahun 2008 tentang & Belum memahami dan belum & Sudah mengetahui UU No. 11 Tahun \\
Informasi dan Transaksi & mengetahui UU No. 11 Tahun 2008 & 2008 \\
Elektronik & & \\
\hline
\end{tabular}

Berdasarkan Tabel 1, hasil evaluasi awal mengenai pegetahuan dan pemahaman siswa dan siswi SMAIT Daarul Ilmi tentang upaya pencegahan penyalahgunaan gadget, menunjukan bahwa siswa dan siswi belum sepenuhnya mengetahui dan memahami upaya pencegahan penyalahgunaan gadget, dampak negatif penyalahgunaan gadget, serta instrumen hukum yang menjerat pelaku penyalahgunaan gadget. Sebelum penyampaian materi, pada umumnya siswa siswi SMAIT Daarul Ilmi hanya mengetahui bahwa gadget merupakan benda dengan teknologi canggih yang bermanfaat untuk mempermudah pekerjaan manusia terutama dalam berkomunikasi. Siswa dan siswi SMAIT Daarul Ilmi belum mengetahui dampak negatif gadget, cara menggunakan gadget tanpa melanggar hukum, cara mencegah penyalahgunaan gadget,dan istrumen hukum yang menjerat pelaku penyalahgunaan gagdet.

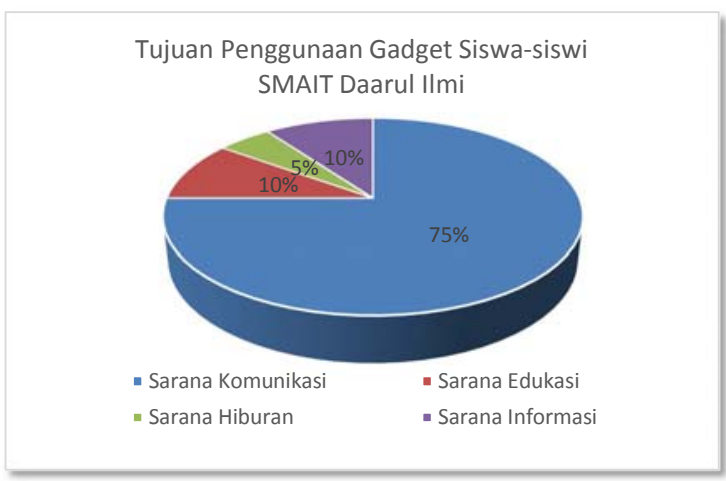

Gambar z. Iujuan penggunaan gaaget pra penyampaian materi

Berdasarkan hasil pre-test (Gambar 2), 75\% siswa dan siswi SMAIT Daarul Ilmi menggunakan gadget untuk sarana komunikasi, 10\% menggunakan gadget untuk sarana edukasi, $5 \%$ menggunakan gadget untuk sarana hiburan, dan 10\% menggunakan gadget untuk mencari berita/informasi. Namun pemahaman mengenai adanya dampak negatif gadget, akibat hukum penyalahgunaan gadget masih kurang. Berdasarkan pengamatan dari hasil pre-test, hampir seluruh siswa mengetahui dampak positif gadget, namun tidak untuk dampak negatifnya. 50\% siswa dan siswi SMAIT Darrul Ilmi menjawab bahwa dampak negatif gadget yakni terhadap kesehatan, padahal masih banyak dampak negatif lain dari penyalahgunaan gadget bahkan bermuara pada pidana. 
ABDIMAS: Jurnal Pengabdian Masyarakat Universitas Merdeka Malang

Volume 5, No 3, November 2020: 257-265

Berdasarkan hasil pre-test, diketahui bahwa cara mencegah penyalahgunaan gadget menurut siswasiswi SMAIT Daarul Ilmi yaitu: (1) Pengawasan orangtua; (2) Perlu banyak waktu bersama orangtua; (3) Bersosialisasi dan berorganisasi; (4) Membuat jadwal penggunaan gadget.

Evaluasi proses pelaksanaan dilakukan dengan melihat partisipasi serta keaktifan peserta dalam kegiatan Sosialisasi dan Focus Group Discussion (FGD) Pencegahan Penyalahgunaan Gadget dan Perlindungan Anak Pada Siwa SMAIT Daarul Ilmi sedang berlangsung. Berdasarkan hasil pengamatan tim pelaksana pengabdian, pasrtisipasi dan keaktifan peserta cukup tinggi, hal ini ditunjukan dengan adanya beberapa pertanyaan yang diajukan peserta kepada para narasumber serta aktif dalam termin diskusi dan tanya jawab. Pada saat penyampaian materi dan diskusi serta tanya jawab, peserta cukup antusias dan terlihat keinginan mereka untuk memahami materi tentang penyalahgunaan gadget dan jeratan hukum bagi pelakunya. Antusiasme peserta ini tentu wajar, terlepas dari minimnya pengetahuan mengenai upaya pencegahan penyalahgunaan gadget dan istrumen hukum yang mengaturnya, materi yang disampaikan pun berbobot dan langsung oleh ahlinya.

Evaluasi akhir dilaksanakan oleh tim pengabdian dengan mengadakan diskusi dan tanya jawab serta memberikan beberapa pertanyaan post-test dan melakukan review terhadap jawaban peserta. Evaluasi ini dimaksudkan untuk mengetahui keberhasilan kegiatan Sosialisasi dan Focus Group Discussion (FGD) Pencegahan Penyalahgunaan Gadget dan Perlindungan Anak pada Siswa SMAIT Daarul Ilmi. setelah penyampaian materi, terlihat ada peningkatan pemahaman siswa-siswi SMAIT Daarul Ilmi mengenai pencegahan penyalahgunaan gadget dan perlindungan anak.

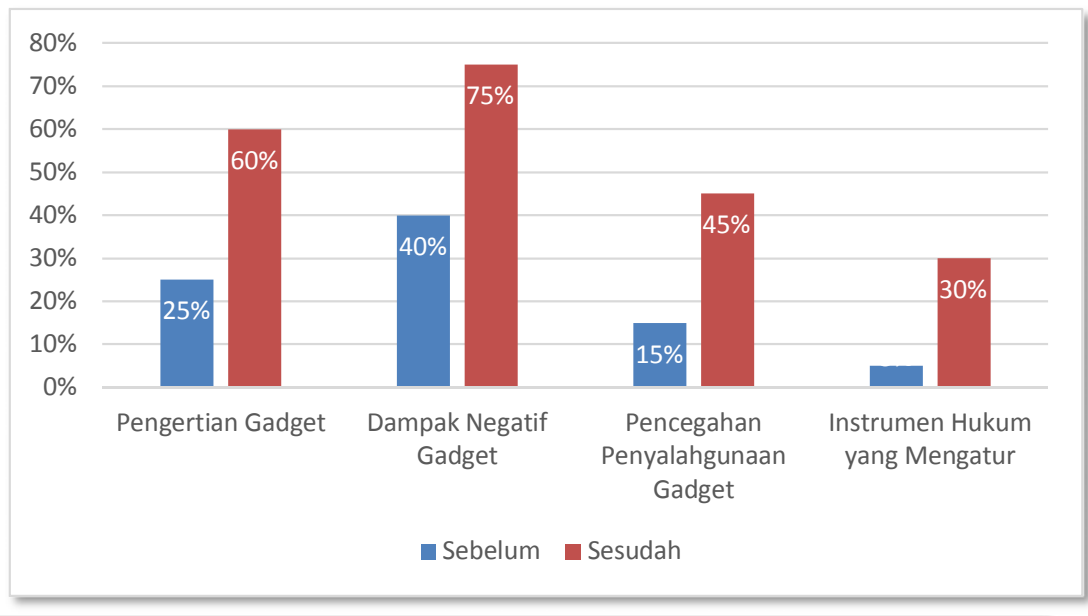

Gambar 3. Tingkat pemahaman sebelum dan sesudah penyampaian materi

Berdasarkan Gambar 3 dapat diketahui bahwa ada peningkatan pengetahuan yang signifikan sebelum dan sesudah penyampaian materi. Sebelum penyampaian materi, pemahaman terhadap pengertian gadget sebesar $25 \%$, setelah penyampaian materi pemahaman meningkat menjadi $60 \%$. Kemudian untuk pemahaman mengenai dampak negatif gadget sebelum penyampaian materi hanya $40 \%$ dan setelah penyampaian materi meningkat menjadi $75 \%$. Pemahaman mengenai pencegahan penyalahgunaan gadget sebelum penyampaian materi yakni 15\% dan setelah penyampaian materi meningkat menjadi $45 \%$. Sedangkan pemahaman mengenai instrumen hukum yang mengatur, sebelum penyampaian materi hanya 
5\% saja, kemudian setelah penyampaian materi meningkat menjadi 30\%. Dengan demikian, kegiatan ini bekontribusi besar dalam peningkatan pengetahuan peserta mengenai pencegahan penyalahgunaan gadget, dampak negatif gadget dan instrumen hukum yang siap menjerat para penyalahguna gadget.

Para peserta mempunyai komitmen kuat dalam mengikuti kegiatan ini. Para peserta berkomitmen untk mengimplementasikan pengetahuan yang di dapat sekaligus merupakan kunci keberhasilan dari sebuah kegiatan transfer pengetahuan. Untuk mewujudkan hal tersebut, para pengabdi melakukan beberapa upaya yakni memberikan pertanyaan pre-test dan post-test, diskusi dan tanya jawab, para pengabdi mencoba memposisikan diri sebagai pendengar keluh kesah para peserta dalam pemanfaatan gadget, dan memberikan edukasi terkait ancaman pidana bagi pelaku penyalahgunaan gadget. Dengan kegiatan ini, para peserta menyatakan senang dan terkesan sehingga menginginkan kegiatan pengabdian ini diadakan kembali namun dengan tema yang berbeda guna meningkatkan wawasan.

Keberhasilan kegiatan Sosialisasi dan Focus Group Discussion (FGD) Pencegahan Penyalahgunaan Gadget dan Perlindungan Anak pada Siswa SMAIT Daarul Ilmi Bukit Kemiling Permai Kota Bandar Lampung, tidak lepas dari beberapa faktor pendukung berikut ini: (1) Pelaksanaan kegiatan dapat terlaksana karena adanya kesempatan baik waktu maupun tempat yang diberikan oleh Kepala Sekolah SMAIT Daarul Ilmi. (2) Antusiasme peserta dalam hal ini siswa-siswi SMAIT Daarul Ilmi yang mengikuti kegiatan ini berjumlah 50 orang. Dalam mengikuti kegiatan ini, peserta tertib dan menyimak penyampaian materi sehingga kegiatan ini berjalan lancar. (3) Peserta cukup gencar bertanya dan berdiskusi dengan para narasumber, hal ini merepresentasikan rasa ingin tahun yang tinggi dari peserta terkait pencegahan penyalahgunaan gadget. (4) Adanya rasa kekeluargaan dan kebersamaan antara tim pengabdian dengan para peserta.

Dukungan penuh Kepala Sekolah, para guru dan siswa-siswi SMAIT Daarul Ilmi yang hadir dan berpartisipasi dalam kegiatan ini. Mengingat adanya beberapa faktor pendukung diatas, pelaksanaan kegiatan Focus Group Discussion (FGD) Pencegahan Penyalahgunaan Gadget dan Perlindungan Anak Pada Siswa SMAIT Daarul Ilmi Bukit Kemiling Permai Kota Bandar Lampung, tidak banyak mengalami hambatan. Sekalipun ada, hambatan tersebut tidak terlalu berarti karena hanya menyangkut masalah teknis penyampaian, dimana bahasan hukum yang harus diuraikan dan dikemas sesuai dengan kemampuan peserta yang pada umumnya awam hukum serta keterbatasan waktu.

\section{SIMPULAN DAN SARAN}

\section{Simpulan}

Kegiatan Sosialisasi dan Focus Group Discussion (FGD) Pencegahan Penyalahgunaan Gadget dan Perlindungan Anak Pada Siswa SMAIT Daarul Ilmi Bukit Kemiling Permai Kota Bandar Lampung telah memberikan pengetahuan dan pemahaman kepada para siswa-siswi SMAIT Daarul Ilmi mengenai pencegahan penyalahgunaan gadget dan perlindungan anak. Hal ini dapat dilihat dari hasil evaluasi, bahwa ada peningkatan pengetahuan dan pemahaman siswa-siswi SMAIT Daarul Ilmi sebelum dan sesudah kegiatan pengabdian. Secara perlahan siswa-siswi SMAIT Daarul Ilmi mulai memahami apa itu gadget, dampak negatif gadget, penanggulangan penyalahgunaan gadget, dan instrumen hukum yang mengatur penyalahgunaan gadget. hasil pertanyaan post-test dapat diketahui juga bahwa $80 \%$ siswa-siswi SMAIT Daarul Ilmi terkesan senang dan menanggap bahwa kegiatan sangat perlu dilakukan untuk menambah pengatahuan dan menginginkan kegiatan Sosialisasi dan Focus Group Discussion (FGD) Pencegahan Penyalahgunaan Gadget dan Perlindungan Anak dilakukan kembali dengan tema yang berbeda. 
ABDIMAS: Jurnal Pengabdian Masyarakat Universitas Merdeka Malang

Volume 5, No 3, November 2020: 257-265

\section{Saran}

Kegiatan penyuluhan hukum perlu ditingkatkan lagi oleh pengabdi selanjutnya melalui penggunaan media komunikasi baik secara daring (dalam jaringan) maupun luring (luar jaringan). Materi sosialisasi/ penyuluhan hukum dibuat lebih menarik, dalam bentuk audio visual seperti pembuatan video pembelajaran agar pengetahuan dan pemahaman hukum kepada siswa dapat disampaikan secara terus menerus. Disamping itu perlu disusun materi tentang pencegahan penyalahgunaan gadget dan perlindungan anak sebagai salah satu materi yang melekat pada kegiatan ekstra kurikuler di sekolah yang berkaitan dengan pembentukan karakter siswa. Kegiatan penyuluhan/sosialisasi ini harus terus berlanjut secara berkesinambungan dan terpadu, baik yang melibatkan Fakultas Hukum Universitas Lampung maupun pihak lain seperti aparat penegak hukum dalam rangka meningkatkan kesadaran hukum masyarakat khususnya terkait pencegahan penyalahgunaan gadget dan perlindungan anak dan hal-hal lain yang dianggap penting dalam penegakan hukum di Indonesia.

\section{DAFTAR PUSTAKA}

Anwar, M., \& Wijaya, M. R. (2020). Fungsionalisasi dan implikasi asas kepentingan terbaik bagi anak yang berkonflik dengan hukum: Studi putusan Pengadilan Tinggi Tanjung Karang. Undang: Jurnal Hukum, 2(2). https://doi.org/10.22437/ujh.2.2.265-292

Chusna, P. A. (2017). Pengaruh media gadget pada perkembangan karakter anak. Dinamika Penelitian: Media Komunikasi Penelitian Sosial Keagamaan, 17(2), 315-330. https://doi.org/10.21274/dinamika.2017.17.2.315-330

Dirgantara, R. (2020). Analisis kejahatan begal dengan motivasi perampokan di Kota Palu. Tadulako Master Law Journal, 4(2), 159-173.

Haryanto, A. T. (2020). Riset: Ada 175,2 juta pengguna internet di Indonesia. detikInet. https:// inet.detik.com/cyberlife/d-4907674/riset-ada-1752-juta-pengguna-internet-di-indonesia (diakses pada 24 Agustus 2020 pukul 21:23 WIB).

Makki, S. (2019). Dua remaja bekasi alami gangguan jiwa akibat kecanduan gim HP. CNN Indonesia. https://www.cnnindonesia.com/nasional/20191017105052-20-440267/dua-remaja-bekasialami-gangguan-jiwa-akibat-kecanduan-gim-hp (diakses pada 24 Agustus 2020 pukul 21:50 WIB).

Manurung, H. A., Warno, N. D., \& Setiyono, J. (2016). Analisis yuridis kejahatan pornografi (cyber porn) sebagai kejahatan transnasional. Diponegoro Law Journal, 5(3), 1-13.

Nurhaeda. (2018). Dampak penggunaan gadget pada anak usia dini dalam pandangan Islam di PAUD Terpadu Mutiara Hati Palu. ECIJ, 1(2), 70-78.

Pertiwi, M. (2020). hubungan penggunaan gadget dengan visus mata pada siswa/i kelas VI SD Harapan 2 Medan tahun 2019. Poltekkes Kemenkes Medan. http://poltekkes.aplikasi-akademik.com/ xmlui/handle/123456789/2056 (diakses pada 24 Agustus 2020).

Rahman, A. (2016). Pengaruh negatif era teknologi informasi dan komunikasi pada remaja (perspektif pendidikan Islam). AL-ISHLAH: Jurnal Pendidikan Islam, 14(1).

https://doi.org/10.35905/alishlah.v14i1.384 
Pencegahan Penyalahgunaan Gadget dan Perlindungan Anak pada Siswa SMAIT Daarul' Ilmi Bandar Lampung Maroni, Erna Dewi, Rini Fathonah, Damanhuri Warganegara, Nenny Dwi Ariani, Mashuril Anwar

Roria, R. (2019). Implementasi Undang-Undang Nomor 35 Tahun 2014 tentang Perlindungan Anak terhadap Perlindungan Hak-Hak Anak Korban Kekerasan Seksual (Studi di Unit Layanan Terpadu Perlindungan Sosial Anak Integratif Kabupaten Tulungagung). Sakina: Journal of Family Studies, 3(3).

Rudiantara, (2018). Pemakaian gadget pada anak dikhawatirkan timbulkan dampak negatif terhadap perkembangan dirinya. Majalahict. http://www.majalahict.com/pemakaian-gadget-pada-anakdikhawatirkan-timbulkan-dampak-negatif-terhadap-perkembangan-dirinya/ (diakses pada 3 April 2019 pukul 20:28 WIB).

Setianingsih, E. S. (2019). Gadget "pisau bermata dua" bagi anak? Seminar Pendidikan Nasional (SENDIKA), 1(1), 397-405.

Zaini, M. \& Soenarto, S. (2019). Persepsi orangtua terhadap hadirnya era teknologi digital di kalangan anak usia dini. Jurnal Obsesi: Jurnal Pendidikan Anak Usia Dini, 3(1), 254-264. https://doi.org/10.31004/obsesi.v3i1.127 